\title{
Morphological and genetic evaluation of the hydrocoral Millepora species complex in the Caribbean
}

\author{
Dannise V Ruiz-Ramos ${ }^{1,2}$, Ernesto Weil ${ }^{1}$ and Nikolaos $\vee$ Schizas $^{1 *}$
}

\begin{abstract}
Background: The hydrocoral Millepora is an important framework builder that dominates shallow turbulent environments in the Indo-Pacific and the Atlantic-Caribbean. The Caribbean representatives of the genus are classified in four species - Millepora alcicornis, Millepora complanata, Millepora striata, and Millepora squarrosa - but their taxonomic boundaries are not clearly defined. We used mitochondrial gene sequences to delineate the four Millepora species and evaluated whether morphological traits and mitochondrial sequence divergence were correlated for two most common species M. alcicornis and M. complanata.
\end{abstract}

Results: Samples were collected from Puerto Rico, Guadeloupe, Curaçao, Grand Cayman, and Panama during 2006 to 2007. Diameter of dactylopores distinguished the branching and encrusting morphotypes of $M$. alcicornis and M. complanata, and gastropore diameter discriminated between M. alcicornis and M. complanata. High levels of haplotypic diversity $\left(H_{d}=0.94\right)$ were observed, with the most common haplotypes shared by $M$. alcicornis and $M$. complanata. Sequence divergence ranged from $0 \%$ to $3 \%$ among $M$. alcicornis, M. complanata, and $M$. striata to $25 \%$ between these three species and $M$. squarrosa. Bayesian analysis of cytochrome oxidase subunit I (COI) gene indicated the presence of three Caribbean taxa: M. squarrosa, M. striata, and the 'species complex' encompassing the morphologies displayed by M. complanata and M. alcicornis.

Conclusions: The branched M. alcicornis and encrusted M. alcicornis and M. complanata can be differentiated morphologically but not genetically. Phylogenetic analysis suggests that the Caribbean milleporids include three species - M. squarrosa, M. striata, and the species complex of M. alcicornis-M. complanata. Millepora striata is closely related to the M. alcicornis-M. complanata species complex.

Keywords: Hydrozoan; Polymorphism; Phenotypic plasticity; Cytochrome oxidase I; Puerto Rico

\section{Background}

The hydrocoral genus Millepora consists of 19 species distributed in warm waters around the globe. Twelve of these are found in the Indo-Pacific and seven in the Atlantic-Caribbean, with no common species between the two oceans (Boshma 1948; Cairns 1999; Amaral et al. 2008). Some Millepora species are important framework builders in some locations as they dominate shallow turbulent environments, forming dense reef rims contributing to the stabilization and complexity of the carbonate structure (Lewis 1989; Edmunds 1999). Additionally, Millepora are

\footnotetext{
* Correspondence: nschizas@gmail.com

'Department of Marine Sciences, University of Puerto Rico, Mayagüez, Call Box 9000, Mayagüez 00681, Puerto Rico

Full list of author information is available at the end of the article
}

voracious plankton feeders, consuming up to 8 prey $\mathrm{cm}^{-2}$ day $^{-1}$ (Lewis 1992).

Milleporids are superior space competitors over gorgonians (Wahle 1980) and are immune to predation by the starfish Acanthaster planci (Lewis 1989). However, Millepora is one the first cnidarians to lose its zooxanthellate symbionts during bleaching events (Glynn 1993; Paulay and Benayahu 1999; Marshall and Baird 2000). Despite their abundance, geographical distribution, and geological importance, the milleporids have seldom received attention in coral reef studies (Lewis 1989). Similar to some groups of scleractinian corals, lack of information is partly due to the high degree of morphological variation within the genus, which renders identification of species difficult. 
The taxonomic status of the various Millepora species has been controversial for more than three and a half centuries (Boshma 1948; Manchenko et al. 1993). Efforts to identify species were mainly based on morphological characters of the corallum (the calcium carbonate skeleton): presence or absence of ampullae (receptacles bearing the sexual medusa), texture of the colony, and number of gastropores and dactylopores (Boshma 1948; de Weerdt 1984; Razak and Hoeksema 2003). However, due to their high morphological variability, disagreement exists on the species classification based on those traits (de Weerdt 1984; Lewis 1989; Amaral et al. 2002). Accepted valid species are those described by Boshma (1948) and later revisited by
Cairns (1999); however, the taxonomic revision of the genus is still in progress. New forms of milleporids are being described and proposed as new species (Amaral et al. 2002, 2008), while a more recent revision examined the range of morphological variation and the validity of the taxonomical characters (Razak and Hoeksema 2003).

Seven species of Millepora are described from the western tropical Atlantic: Millepora alcicornis Linnaeus 1758, Millepora complanata Lamarck 1816, Millepora squarrosa Lamarck 1816, Millepora striata Duchassaing and Michelotti 1864, Millepora nitida Verrill 1868, Millepora braziliensis Verrill 1868, and Millepora laboreli Amaral et al. 2008; the last three are restricted to Brazil. The species

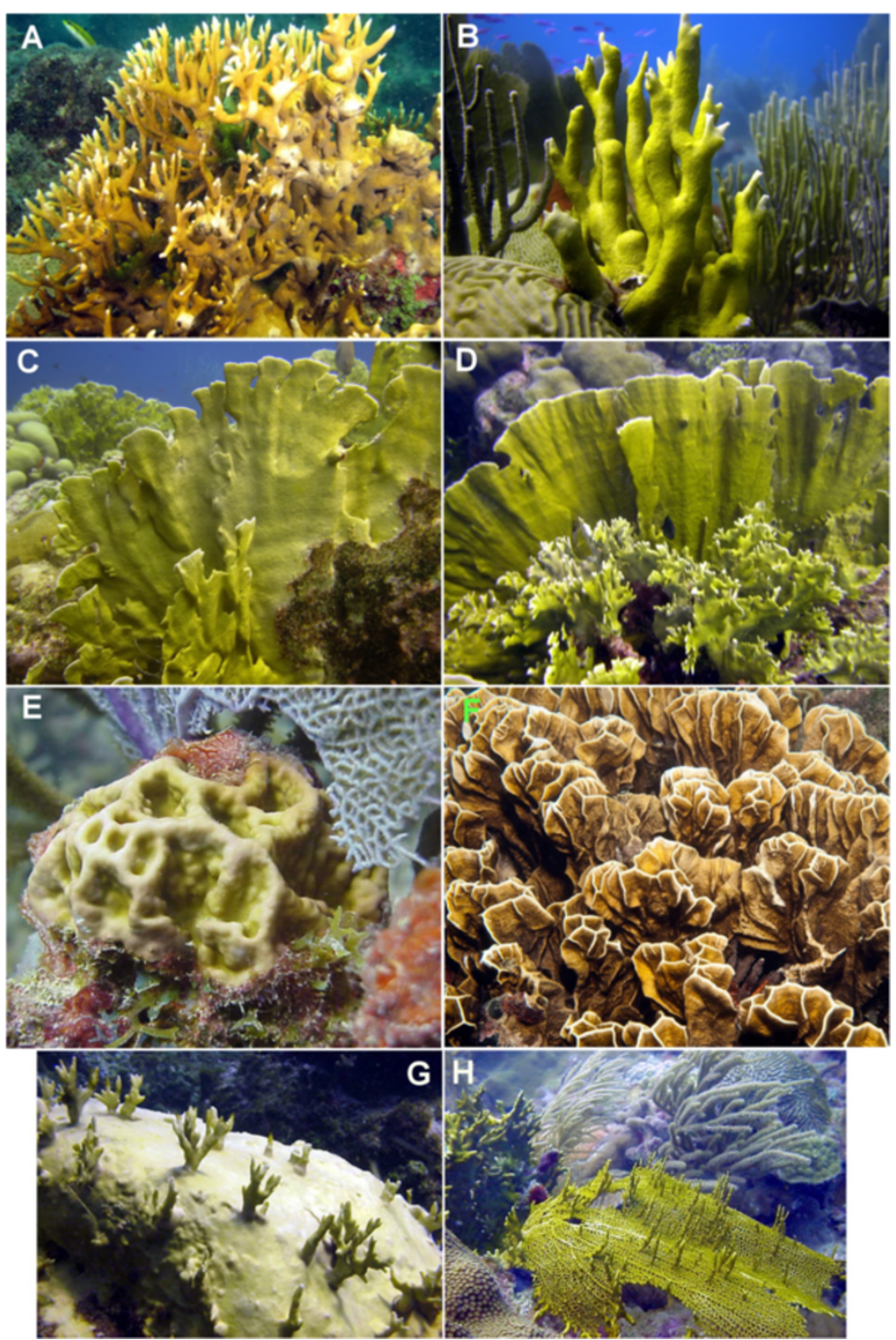

Figure 1 The different described species of Millepora in the Caribbean. Typical M. alcicornis colony from Puerto Rico (A), and a different thicker ecomorph (or a potentially different taxon) common in Bermuda (B). A typical colony of M. complanata (C), and M. alcicornis (front) and M. complanata (back) coexisting in the same habitat in Curaçao (D). Medium size M. squarrosa in Puerto Rico (E), and the rare M. striata from Honduras (F). Several different ecomorphs of Millepora (some crustose aggressive colonizers of substrate) $\mathbf{( G )}$, and some killing and colonizing octocorals (H). (Photos by E. Weil) 
in this study included $M$. alcicornis, M. complanata, $M$. squarrosa, and M. striata (Additional file 1, Figure 1).

M. alcicornis is abundant in the Caribbean, Bermuda, Brazil, and West Africa, primarily at less exposed areas of reefs and lagoons (de Weerdt 1984; Lewis 2006). Colonies are branching; branches may be very delicate or coarse and largely united into plate-like constructions with flattened growing edges. The corallum grows mostly upright, but it may also encrust other sessile organisms and hard substrates. The surface of the colony is smooth and even, and the gastropore size ranges from 0.15 to $0.30 \mathrm{~mm}$, while the dactylopores are small $(0.06$ to $0.17 \mathrm{~mm})$ (de Weerdt 1984).

M. complanata is also common throughout the Caribbean (de Weerdt 1984; Lewis 2006), inhabiting the surf zone and reef flats. The colonies are formed by simple plates growing from a common base or may create complex honeycomb-like structures of interconnected plates. The plates grow perpendicular to the direction of the current, but in places with strong wave action, colonies may remain as a large encrusting base. The surface of the colonies varies from smooth to rough. The gastropores are large $(0.22$ to $0.36 \mathrm{~mm})$, and dactylopores are variable in size (0.12 to $0.24 \mathrm{~mm})$.

$M$. squarrosa is restricted in the northeastern, eastern, and southeastern Caribbean and is also reported for Brazil (de Weerdt 1984, 1990). The colonies consist of irregular, heavy-connected, thick masses with smooth rounded edges. In older colonies, the growth form can become more plate-like and the growing edges sharper, but the plates remain connected along their whole length, resulting in a box-work structure. The surface is smooth but irregular due to the presence of crests and tubercles. Gastropore size varies from 0.20 to $0.30 \mathrm{~mm}$, and the dactylopores vary from 0.07 to $0.15 \mathrm{~mm}$.

M. striata is reported from Panama, Colombia, Venezuela and Guadeloupe (de Weerdt 1984), and Belize (Fenner 1999). Colonies are formed by loosely connected plates of very sharp edges with a strong tendency to divide along the upper edge. Longitudinal folds make the surface very uneven. Gastropores grow to sizes from 0.15 to $0.25 \mathrm{~mm}$, and dactylopores vary from 0.08 to $0.18 \mathrm{~mm}$.

The few taxonomical studies on the Caribbean Millepora highlight the high degree of skeletal polymorphism encountered in the genus. Two previous studies (Martínez-Estalella 1982; de Weerdt 1984) concluded that species distinctions were uncertain due to the high morphological variability among the colonies within each taxon and the overlap of skeletal characteristics between species. Additionally, reciprocal transplantation experiments (de Weerdt 1981) suggested that environmental factors might influence the colony shape. Even though controversy persists around the genus Millepora, little has been done to unravel its taxonomic ambiguity by using multicharacter approaches including molecular techniques, such as those used with scleractinian corals (Weil and Knowlton 1994). The few available studies focused on species from Vietnam, the Red Sea, Brazil, and Bahamas (Manchenko et al. 1993; Meroz-Fine et al. 2003; Amaral et al. 2008; Squiers et al. 2011).

The purpose of this study was to combine a morphologically based Millepora classification scheme with new molecular information based on the mitochondrial gene cytochrome oxidase subunit I (COI) to test whether different morphotypes of $M$. alcicornis and $M$. complanata represent genetically distinct taxa. The four Millepora species were evaluated genetically in an attempt to clarify the status of the Millepora species reported from Caribbean waters.

\section{Methods}

\section{Sampling methods}

Samples were collected from the fringing reefs of Turrumote $\left(17.934^{\circ} \mathrm{N}, 67.018^{\circ} \mathrm{W}\right)$, Media Luna $\left(17.938^{\circ} \mathrm{N}\right.$, $\left.67.041^{\circ} \mathrm{W}\right)$, Enrique $\left(17.954^{\circ} \mathrm{N}, 67.051^{\circ} \mathrm{W}\right)$, Las Pelotas $\left(17.956^{\circ} \mathrm{N}, 67.073^{\circ} \mathrm{W}\right)$, and Margarita $\left(17.922^{\circ} \mathrm{N}, 67.097^{\circ} \mathrm{W}\right)$ in La Parguera, southwest coast of Puerto Rico (PR) (Additional file 2) at depths between 1 and $15 \mathrm{~m}$. $M$. squarrosa was collected at Media Luna and Turrumote reefs at depths of $15 \mathrm{~m}$. All samples were collected during 2006 to 2007. Colonies were classified as M. alcicornis, $M$. complanata, M. squarrosa, or M. striata (Additional file 1, Figure 1), using the most recent taxonomic descriptions for the Caribbean species (de Weerdt 1984). In addition, sequences of $M$. alcicornis and $M$. complanata from seven localities across the Caribbean were added for genetic analysis: Bocas del Toro, Panama $\left(9.231^{\circ} \mathrm{N}, 82.137^{\circ} \mathrm{W}\right)$; Grand Cayman; Mona, Puerto Rico (PR) $\left(18.105^{\circ} \mathrm{N}, 67.940^{\circ} \mathrm{W}\right)$; La Parguera, PR $\left(17.970^{\circ} \mathrm{N}, 67.046^{\circ} \mathrm{W}\right)$; Vieques, PR $\left(18.119^{\circ} \mathrm{N}, 65.577^{\circ} \mathrm{W}\right)$; Guadeloupe; and Curaçao $\left(12.084^{\circ} \mathrm{N}\right.$, $\left.68.896^{\circ} \mathrm{W}\right)$. COI sequences from $M$. striata collected from Bocas del Toro, Panama were also included in the analysis.

M. alcicornis was divided into two morphotypes (Additional file 3): free growth (from now on referred as branching) and the encrusting form that covers substrata and octocorals (crustose or laminar). de Weerdt (1984) and Lewis (1989) identified Millepora growing on gorgonians as M. alcicornis; however, colonies of both M. alcicornis and M. complanata have been observed overgrowing gorgonians (Wahle 1980; Squiers et al. 2011; all authors, personal observation). There is a wide morphological variability of Millepora overgrowing octocoral colonies, but we only included colonies that were tentatively identified as $M$. alcicornis by the gross morphology of the colony (forming delicate branches, instead of plates) to reduce the range of morphotypes considered within the encrusting forms. All these specimens were treated as a distinct morphotype from other $M$. alcicornis.

M. squarrosa was relatively common in Puerto Rico (de Weerdt 1984, 1990), before the 2005 bleaching event (EW, 
unpublished data). Surveys after the bleaching event failed to find a single colony in several reefs off La Parguera (EW, unpublished data). Only three colonies were found in three reefs (Turrumote, Media Luna, and Margarita) during the duration of the study (2006 to 2007). Tissue was collected only for genetic analysis, due to the small size of the colonies. Only two of the colonies were used (Turrumote and Media Luna) because the amplification from the Margarita sample was unsuccessful. M. striata has not been reported from Puerto Rico; four specimens were obtained from Bocas del Toro, Panama and used in the genetic analysis.

Ten colonies each of the most representative morphotypes of $M$. alcicornis branched (Mab), M. alcicornis encrusted (Mae), and M. complanata (Mc) were sampled $(N=30)$ from the front reef within a depth range of 0.5 to $9 \mathrm{~m}$, following a linear transect. Selected colonies were spaced at least $5 \mathrm{~m}$ from each other to minimize the collection of clones. Two fragments of each colony were collected and preserved in $100 \%$ ethanol for micromorphological and genetic analyses.

\section{Morphological variability}

The 30 colonies $(\mathrm{Mab}=10$, Mae $=10$, and $\mathrm{Mc}=10)$ used for the morphometric analysis were collected in the reef crest of Enrique cay to ensure that colonies faced similar conditions during life (de Weerdt 1984). A $3-\mathrm{cm}^{2}$ fragment of each colony was used for DNA extraction, and the remainder was cleaned with $5 \%$ sodium hypochlorite solution, dried, and analyzed under an Olympus SZH10 stereo microscope (Olympus, Tokyo, Japan) following the procedure by Amaral et al. (2002). Five skeletal characters that have been commonly used in previous Millepora taxonomic studies were selected for the morphometric analysis: (1) diameter of the dactylopores, (2) diameter of gastropores (de Weerdt 1984; Amaral et al. 2002), (3) distance between the gastropores (Razak and Hoeksema 2003), (4) distance between the dactylopores, and (5) distance from gastropore to the nearest dactylopore (Additional file 4; Table two in Ruiz-Ramos (2009)).

Photographs of the surface of each colony were taken at $\times 30$ magnification with an Olympus C-5050 camera system attached to the Olympus SZH10 stereo microscope and digitally catalogued. The selected traits were measured using SigmaScan Pro software (SPSS Inc.) after calibrating with a stage micrometer calibration slide of $10 \mu \mathrm{m}$ accuracy.

Thirty measurements were taken from each trait of the three morphotypes (Table two in Ruiz-Ramos (2009)). To reduce intraspecific variation, the measures were taken at the center of the wave-facing side of the colonies. Parametric and non-parametric (when data did not meet the assumptions of equal variances and normality) one-way ANOVAs were used to test the hypothesis that there were no significant morphological differences between the three taxa. A posteriori Tukey's test was used to identify the colonies or species that exhibited significantly different traits. A discriminant function analysis (DFA) was used to test the utility of the five morphological characters to distinguish the pre-grouped colonies identified during the collection. The statistical analyses were performed in InfoStat version 2004 (Grupo InfoStat, FCA, Universidad Nacional de Córdoba, Argentina), SigmaStat (SPSS Inc., Chicago, IL, USA), and JMP version 5.0.1 (SAS Institute Inc., Cary, NC, USA). Voucher specimens used in this study have been deposited in the Museum of Marine Invertebrates, Department of Marine Sciences, University of Puerto Rico, Mayagüez.

\section{Genetic analyses}

Genetic analyses were performed for the 30 colonies used in the morphological analysis; four samples of $M$. striata and two of M. squarrosa were also added (Additional file 1). Tissue was scraped from the skeletal surface of the colony and DNA extracted using the PureGene DNA isolation kit (Gentra Systems, Inc., Minneapolis, MN, USA).

Initial gene amplifications were made with the COI primers designed by Fukami et al. (2004), but they were suboptimal. Millepora-specific primers COIF (5'-TAGA ATTAGCTGGGCCAGGA-3') and COIR (5'-CCTGTC TGTAAGCAGCATGG-3') were designed from the initial COI sequences using the Primer 3 software. PCR cycling conditions consisted of an initial denaturation of $3 \mathrm{~min}$ at $95^{\circ} \mathrm{C}$ followed by 35 cycles of $15 \mathrm{~s}$ at $95^{\circ} \mathrm{C}$ for denaturation, $30 \mathrm{~s}$ at $50^{\circ} \mathrm{C}$ of annealing, $60 \mathrm{~s}$ at $72^{\circ} \mathrm{C}$ for extension, and a final extension at $72^{\circ} \mathrm{C}$ for $5 \mathrm{~min}$. Successful PCR reactions were verified by running $5 \mu \mathrm{l}$ of the amplicon on a $1 \%$ TBE agarose gel stained with ethidium bromide. PCR reactions were cleaned of excess dNTPs, primers, and other impurities by enzymatic treatment with the EXOSAP-IT (Affymetrix) method. Sequencing reactions with each of the primers were prepared with the 3.1 BigDye Termination Kit (Applied Biosystems, Foster City, CA, USA) and were loaded in an ABI 3130xl (Applied Biosystems).

DNA sequencing trace files were processed with CodonCode Aligner (CodonCode, Dedham, MA, USA) and exported to MacClade v. 4.05 (Maddison and Maddison 2000) for alignment. The final sequence alignment used for the analyses was 385 bp long. General summary statistics and population analysis were performed with DnaSP (Rozas et al. 2003) (Additional file 5). DNA neutrality tests such as Tajima's $D$ (Tajima 1989) were computed to test for deviation from the neutral model of molecular evolution (Kimura 1968). Numbers of shared mutations, fixed differences, and $F_{\mathrm{ST}}$ values were calculated in DnaSP.

Haplotype networks were drawn with TCS 1.21 (Clement et al. 2000). Phylogenetic trees of the samples were constructed using Bayesian inference (BI) and 
maximum likelihood. The AIC criterion in ModelTest (Posada and Crandall 1998) was used to identify the best substitution model for the COI sequences. Maximum likelihood (ML) analysis was performed in PAUP 4.10b (Swofford 2002) with the Tamura-Nei substitution model (Tamura and Nei 1993) as suggested by ModelTest, with unequal base frequencies $(A=0.22, C=0.23, G=0.18$, $T=0.36$ ), probability of invariable sites $=0.70$, and gamma distribution parameter of $\alpha=1.768$. The BI analysis was run in MrBayes (Ronquist and Huelsenbeck 2003) using the HKY substitution model and gamma distribution, with four mcmc chain runs for 1,100,000 generations. Topology robustness was evaluated with 100 bootstrap replicates (Felsenstein 1985) and posterior probabilities.

DNA sequences $(n=274)$ of the Millepora species and morphotypes sampled across the Caribbean were added to the sequences from the colonies used in the morphological and genetic analyses. An analysis of molecular variance (AMOVA) (Excoffier et al. 1992) was performed to test if the $M$. complanata, $M$. striata, and the two morphotypes of $M$. alcicornis were significantly differentiated within and across populations. A total of seven populations was included in the analysis: Panama (4 Ms-Panama, 10 Mc-Panama, 21 Mab-Panama), Grand Cayman (6 Mc-GC, 7 Mab-GC, 4 Mae-GC), Mona (7 Mc-Mona, 17 Mab-Mona, 20 Mae-Mona), Parguera (24 Mc-Parguera, 56 Mab-Parguera, 33 Mae-Parguera), Vieques (4 Mc-Vieques, 8 Mab-Vieques, 6 Mae-Vieques), Guadeloupe (4 Mc-Gd, 5 Mab-Gd, 2 Mae-Gd), and Curaçao (16 Mc-Curaçao, 14 Mab-Curaçao, 6 MaeCuraçao), where $\mathrm{Ms}=M$. striata, $\mathrm{Mc}=M$. complanata, $\mathrm{Mab}=M$. alcicornis branched, and $\mathrm{Mae}=M$. alcicornis encrusted. AMOVA analysis was performed in Arlequin v3.11 (Excoffier et al. 2005) with 25,000 replications, corrected by the Tamura-Nei $+(\Gamma=1.8)$ model of nucleotide substitution. Genetic differences were partitioned among populations, among morphotypes within populations and within the Caribbean. Pairwise genetic comparisons of the morphotypes were corrected with the Tamura-Nei distance. Phylogenetic trees of the Caribbean-wide Millepora were constructed by $\mathrm{BI}$ analysis using MrBayes (Ronquist and Huelsenbeck 2003) using the HKY substitution model and gamma distribution, with four mcmc chain runs for $1,100,000$ generations. Topology robustness was evaluated with 100 bootstrap replicates (Felsenstein 1985) and posterior probabilities. All sequences have been submitted to GenBank [KC570466 - KC570844].

\section{Results and discussion Results Variability of skeletal characters}

There were significant differences (ANOVA, $p<0.0001$ ) in morphological traits among $M$. complanata, $M$. alcicornis branched, and M. alcicornis encrusted (Table two in RuizRamos (2009)). Mean gastropore diameter (in millimeters) was significantly larger (ANOVA, $p<0.001$ ) in $M$. complanata $(0.25 \pm 0.03 \mathrm{~mm})$ compared to $M$. alcicornis $(0.20 \pm$ $0.04 \mathrm{~mm})$, but similar between the two morphotypes of $M$. alcicornis $(0.20 \pm 0.4 \mathrm{~mm})$. M. complanata had significantly larger dactylopores (ANOVA, $p<0.001)(0.15 \pm$ $0.02 \mathrm{~mm})$ compared to $M$. alcicornis encrusted $(0.13 \pm$ $0.02 \mathrm{~mm})$ and $M$. alcicornis branched $(0.12 \pm 0.02 \mathrm{~mm})$, but there was no significant difference between the two morphotypes of $M$. alcicornis. The diameters of the gastropores and dactylopores of $M$. complanata and $M$. alcicornis were similar to those previously reported by de Weerdt (1984).

Mean distance (in millimeters) between gastropores was significantly (ANOVA, $p<0.001$ ) larger in $M$. alcicornis encrusted $(1.45 \pm 0.43 \mathrm{~mm})$ compared to $M$. alcicornis branched $(1.38 \pm 0.38 \mathrm{~mm})$, while $M$. complanata had the smallest values $(1.10 \pm 0.32 \mathrm{~mm})$. The average distance from gastropore to the nearest dactylopore was significantly larger in $M$. alcicornis branched $(0.40 \pm$ $0.09 \mathrm{~mm}$ ) compared to $M$. complanata and $M$. alcicornis encrusted which had similar mean gastropore-dactylopore distances $(0.36 \pm 0.09 \mathrm{~mm})$ (ANOVA, $p<0.0001$, Table two in Ruiz-Ramos (2009)).

\section{Variability within morphotypes}

Morphometric variation across colonies was significant $(p<0.001)$ for all the traits measured (Figures five, six, seven, eight, and nine in Ruiz-Ramos (2009)). Differences in the diameter of dactylopores and gastropores and in the distances between the pores were observed among colonies of the three morphotypes and also among colonies of the same morphotype. Some colonies with different morphologies (i.e., $M$. complanata and $M$. alcicornis encrusted) showed skeletal traits with similar dimensions.

Mean diameters of gastropores varied from $0.20 \pm 0.03$ to $0.25 \pm 0.03 \mathrm{~mm}$ (Figure five in Ruiz-Ramos (2009)) Gastropore diameters overlapped in the two M. alcicornis morphotypes and were highly variable in colonies within and between morphotypes. There were significant differences (ANOVA, $p<0.0001$ ) among the mean gastropore diameters between colonies within $M$. complanata with values ranging between 0.16 and $0.32 \mathrm{~mm}$ $( \pm 0.03)$. The size of the gastropores of colonies MabCO2, MabMg1, MaeLP9, MaeLP10, and MaeMg1 was significantly larger than that of the other $M$. alcicornis colonies and very similar to the gastropore diameters of $M$. complanata.

Dactylopore mean diameter varied from $0.11 \pm 0.02$ to $0.15 \pm 0.02 \mathrm{~mm}$ (Figure six in Ruiz-Ramos (2009)). M. complanata exhibited the largest dactylopores, while the smaller were observed in the colonies of the branching 
M. alcicornis. The encrusted $M$. alcicornis had the most variable dactylopore size, between 0.05 and 0.20 with a mean size of $0.13 \pm 0.02$. Some colonies, for example, MaeLP2 and MaeLP3, were very similar to M. alcicornis branched, while other colonies such as MaeLP9 were more similar to M. complanata. However, some colonies of the three morphotypes (McMg9, McE3, MabCO2, MaeLP7, MaeLP10, and MaeT15) showed similar mean diameters $(0.13 \pm 0.02)$.

Mean distances between dactylopores (Figure seven in Ruiz-Ramos (2009)) varied from $0.51 \pm 0.10$ to $0.53 \pm$ $0.16 \mathrm{~mm}$ in the majority of the colonies from all the morphotypes, except MabT26 whose average distances were larger than the rest of the colonies.

The mean distances from gastropore to the nearest dactylopore were also variable (Figure eight in Ruiz-Ramos (2009)). There were significant differences among colonies within the morphotypes (ANOVA, $p<0.001$ ), but not among all morphotypes $(p \leq 0.05)$. For example, colonies of branched $M$. alcicornis were more similar to those of
$M$. complanata than they were to those of the encrusted M. alcicornis (Figure eight in Ruiz-Ramos (2009)).

Distances between gastropores were less variable among colonies of the same morphology than the aforementioned traits (Figure nine in Ruiz-Ramos (2009)). The mean distance between gastropores was smaller in $M$. complanata $(1.10 \pm 0.32 \mathrm{~mm})$ than in the $M$. alcicornis morphs. Colonies of branched M. alcicornis $(1.38 \pm 0.39 \mathrm{~mm})$ were also distinct from colonies of encrusted $M$. alcicornis $(1.45 \pm 0.43 \mathrm{~mm})$; still, overlapping measurements were recorded among some colonies of the two morphotypes.

In the three morphotypes ( $M$. alcicornis branched, $M$. alcicornis encrusted, and M. complanata), we found colonies in which their micro-morphological traits were more similar to colonies of other morphotypes than to their own.

\section{Variability across morphotypes}

Despite some overlap among morphological traits, most characters were diagnostic to differentiate species. The diameters of the gastropores of $M$. complanata were

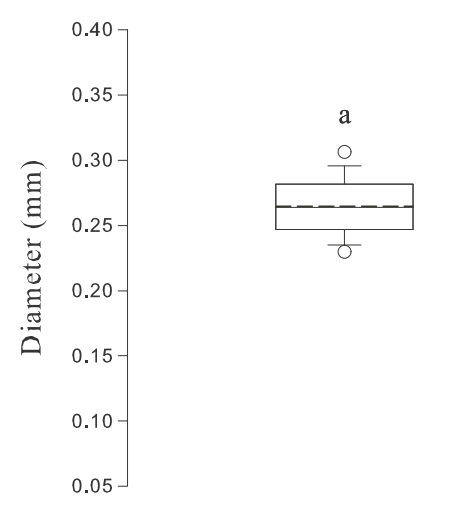

\section{Gastropore diameter}

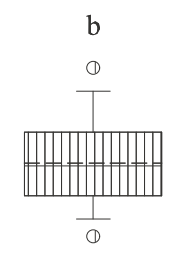

$\mathrm{p}<0.001$
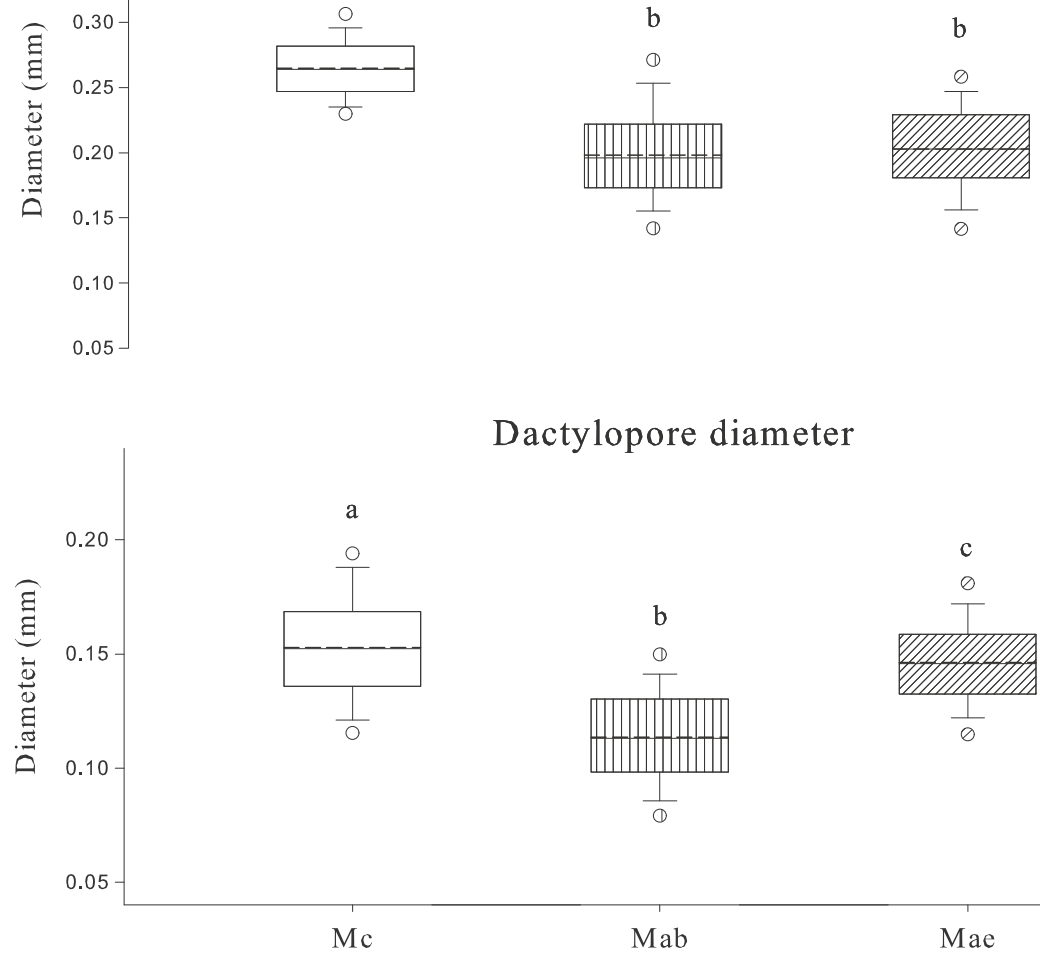

Dactylopore diameter
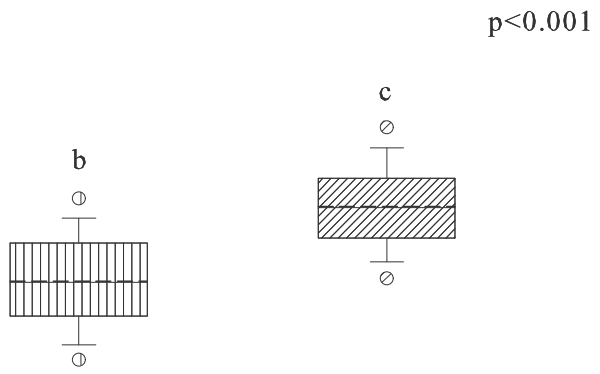

$$
\begin{aligned}
& \text { Mab } \\
& \text { Morphotypes }
\end{aligned}
$$

Figure 2 Variability (mean, median, and 5th and 95th percentiles) in the skeletal traits of Millepora. The top graph shows variability in gastropore diameter, and the bottom graph shows variability in dactylopore diameters. The solid line is the median, and the dashed line is the mean. The white boxes represent M. complanata (Mc), boxes with vertical lines are M. alcicornis branched (Mab), and boxes with diagonal lines is M. alcicornis encrusted (Mae). Letters above the boxes are values of Tukey's test $(p<0.05$ for gastropore diameter, $p<0.001$ for dactylopore diameter); significant differences among morphotypes are denoted by different letters. 
significantly larger (Tukey's test, $p<0.0001$; Figure 2) than in the two morphotypes of $M$. alcicornis. The diameters of the dactylopores were different enough $(p<0.001)$ to distinguish not only between $M$. complanata and $M$. alcicornis but also between the two morphs of $M$. alcicornis. Dactylopore diameters of $M$. complanata were larger $(p<0.0001)$ than those of $M$. alcicornis morphotypes. The dactylopores of $M$. alcicornis encrusted were larger than those of the branched morphotype (Figure 2).

The distances between dactylopores did not differ among $M$. complanata and the two morphotypes of $M$. alcicornis (Additional file 6). The distances from gastropore to the nearest dactylopore and the distance between gastropores were significantly different $(p<0.001)$ among $M$. complanata and the two morphotypes of $M$. alcicornis (Additional file 6). However, the distance between gastropores was highly variable within morphotypes, ranging from 0.26 to $2.95 \mathrm{~mm}$ in the encrusted $M$. alcicornis, from 0.33 to $2.88 \mathrm{~mm}$ in the branched $M$. alcicornis, and from 0.30 to $2.22 \mathrm{~mm}$ in M. complanata. Gastropores were more scattered in the encrusted $M$. alcicornis than in the branched $M$. alcicornis, while the colonies of $M$. complanata had the smaller distances between gastropores.
The canonical discriminant function analysis (Wilk's $\lambda=0.145, F=7.79, p<0.0001)$ corroborated the a priori assigned groups, with $87.1 \%(n=26)$ of the colonies correctly classified (Figure 3 ). Six colonies were misclassified: one $M$. complanata (McMg3), two branched $M$. alcicornis (Mab1, MabT23), and three encrusted M. alcicornis (MaeMg1, MaeLP3, MaeLP5). None of these colonies was misclassified in the phylogenetic analysis (see below, Figure 4). The canonical plot showed three main groups corresponding to the three taxa (Figure 3). $M$. complanata was the most distinct morph. The two morphs of $M$. alcicornis were also differentiated in the plot, although $30 \%$ of the colonies (three of each morph) had similar values. A wide range of values for the $M$. alcicornis morphotypes was also observed, illustrating the high trait variability of the colonies. Dactylopore diameter was the variable that better discriminated $M$. complanata from the $M$. alcicornis morphotypes, while distance from gastropore to the nearest dactylopore distinguished the two morphotypes of M. alcicornis.

\section{Molecular studies}

After editing and end-trimming of the DNA traces, a portion (385 bp) of the mitochondrial COI gene was

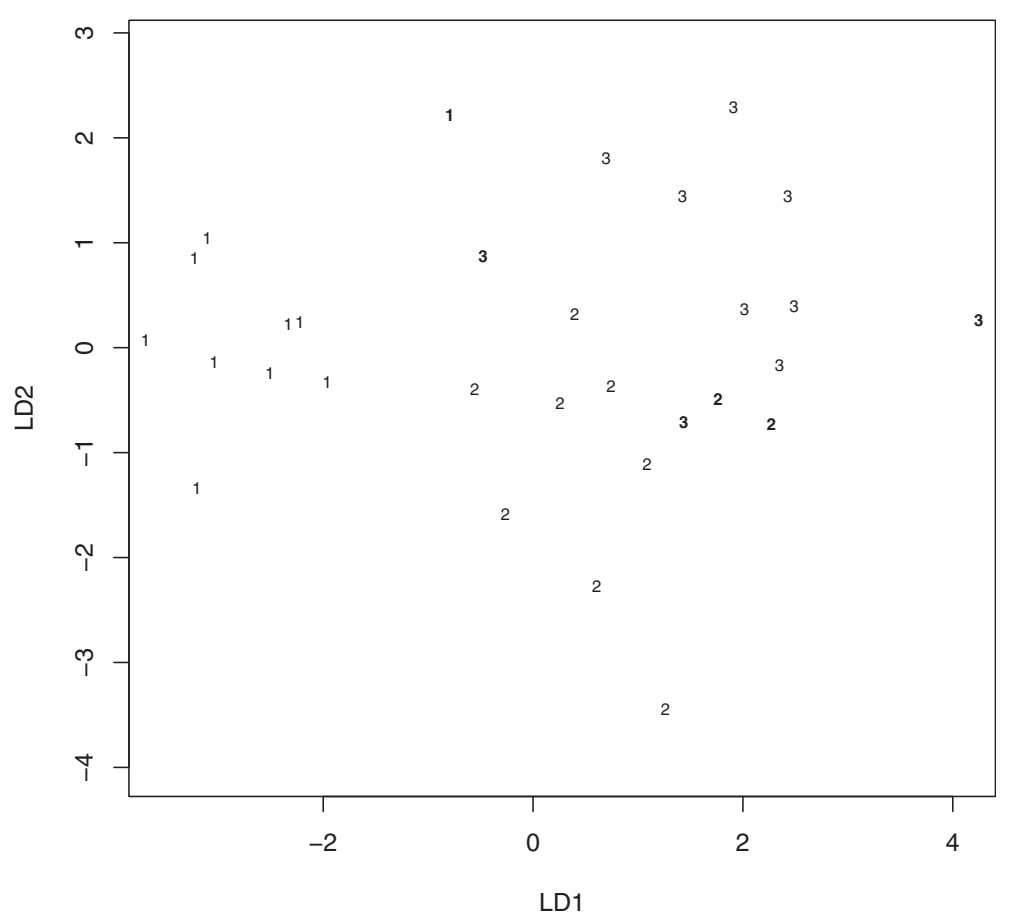

Figure 3 Discriminant function analysis canonical plot based on the morphological traits of the three Millepora morphotypes. Multivariate comparisons (fixed effects MANOVA) among morphotypes were significant (Wilk's $\lambda=0.145, F=7.79, p<0.0001$ ). Misclassified colonies $=6(20 \%)$, are show in bold. Number 1 represent colonies of M. complanata (Mc), no. 2 are colonies of M. alcicornis branched (Mab), and no. 3 are colonies of M. alcicornis encrusted (Mae). Variables for comparison were as follows: D, dactylopore diameter; G, gastropore diameter; G-D, from gastropore to the nearest dactylopore; $G-G$, distances among gastropores; and $D-D$, distances among dactylopores. In canonical axes 1 and 2, distances among dactylopores and gastropores, and gastropore diameters were the variables with more weight in the discrimination. 


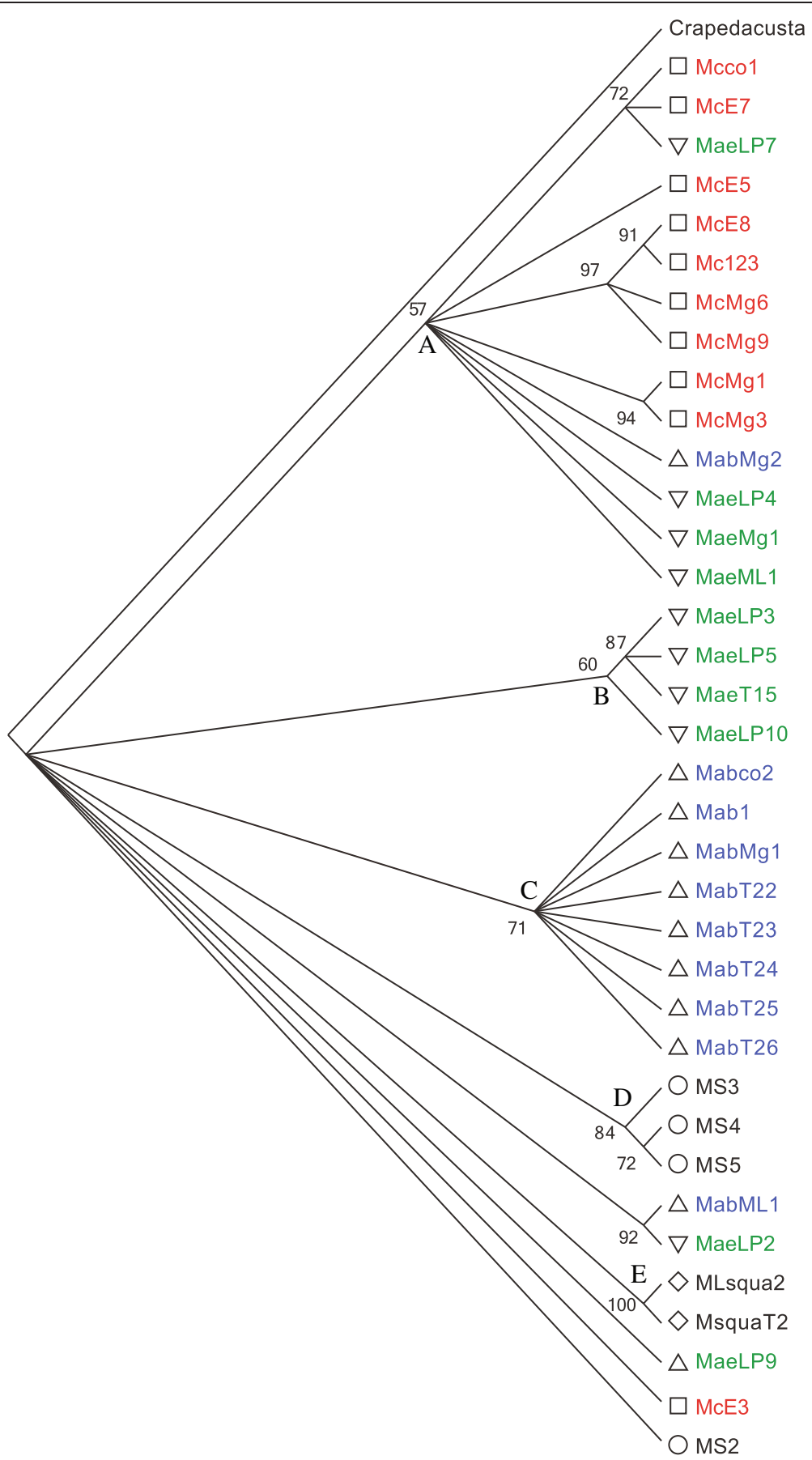

Figure 4 Bayesian phylogeny of Millepora colonies used for morphological analyses (based on COI sequences). Posterior probabilities over $50 \%$ are shown. Shapes represent morphotypes: square, $M$. complanata; upside triangle, $M$. alcicornis branched morph; downside triangle, $M$. alcicornis encrusted morph; circle, M. striata; diamond, M. squarrosa. Names of specimens have been color-coded: red, M. complanata; blue, $M$. alcicornis branched morph; green, M. alcicornis encrusted morph. The hydrozoan Crapedacusta sp. is used as outgroup [GenBank:FJ423620].

used for the genetic analyses. Each colony used for the morphological study was sequenced to measure levels of variation in COI. COI sequences of the other Caribbean species were added to the data set, for a total of 36 sequences (10 M. complanata, 10 M. alcicornis branched,
10M. alcicornis encrusted, 4M. striata, and $2 M$. squarrosa).

Overall, 25 haplotypes were identified, with $70 \%$ of the sequences being unique (Figure 5). Of those haplotypes, six belong to $M$. complanata, five to $M$. alcicornis 


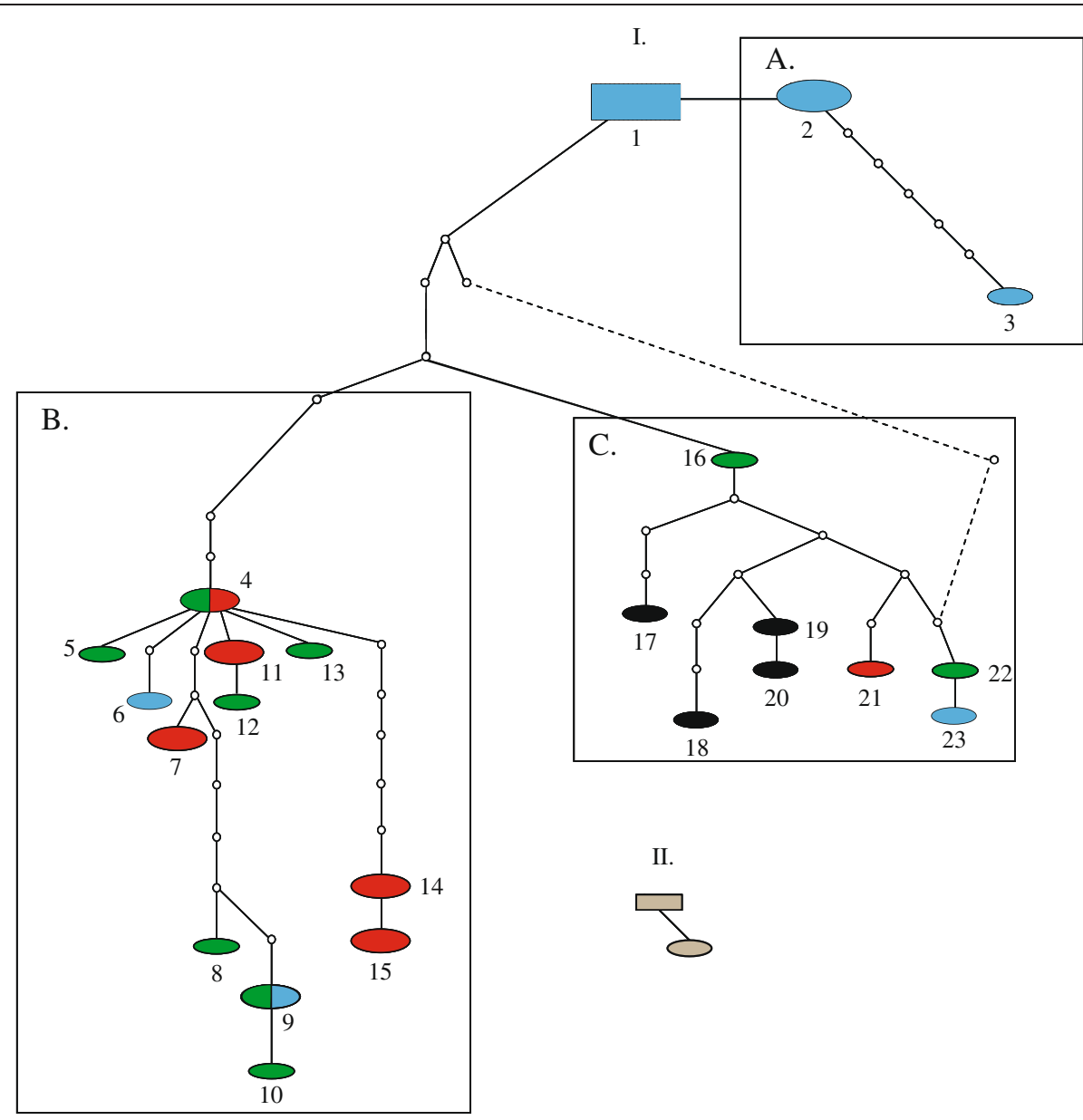

Figure 5 Parsimony haplotype network of the morphotypes based on COI sequences. Patterns represent morphotypes: red ovals, $M$. complanata; blue ovals, M. alcicornis branched morph; green ovals, M. alcicornis encrusted morph; black, M. striata; grey, M. squarrosa. Squares represent ancestral haplotypes. Size of the ovals and squares is proportional to the observed number of sequences corresponding to the haplotype. Small circles are non-sampled or extinct haplotypes. Dashed lines represent alternative connections among the haplotypes, suggesting the presence of homoplasy. Haplotype network I contains M. complanata, M. alcicornis branched morph, M. alcicornis encrusted morph, and M. striata, where $\mathbf{A}, \mathbf{B}$, and $\mathbf{C}$ are the main clusters. Haplotype network II is formed by M. squarrosa.

branched, nine to $M$. alcicornis encrusted, four to $M$. striata, and two to M. squarrosa (Figure 5). Almost all of the most common haplotypes were shared among morphotypes of $M$. alcicornis and M. complanata, across the Caribbean. One haplotype (no. 4) was shared among $M$. complanata and the encrusted morph of $M$. alcicornis, and the other (no. 9) was shared by the two morphotypes of $M$. alcicornis. All the M. striata and $M$. squarrosa haplotypes were unique and were not shared by any other species. Nucleotide diversity $(\pi)$ and Watterson's theta $\left(\theta_{\mathrm{w}}\right)$ were similar for all the morphotypes/species, varying from 0.01 to 0.02 (Additional file 5). Tajima's $D$ values suggested that the COI sequences did not deviate significantly from neutrality.

Divergence among $M$. alcicornis, $M$. complanata, and $M$. striata was low, with $M$. striata more genetically different from $M$. complanata than from $M$. alcicornis.
Despite the absence of fixed differences among all pairwise comparisons (excluding M. squarrosa), M. striata and $M$. complanata had the highest average nucleotide difference (approximately $12 \%$ in Additional file 7). $M$. striata shared four segregating sites with $M$. complanata and the two morphs of $M$. alcicornis. On average, there were nine nucleotide differences between $M$. striata and both morphs of $M$. alcicornis. M. complanata shared seven mutations with $M$. alcicornis branched (average nucleotide difference of approximately 9.2\%) and $11 \mathrm{mu}$ tations with the encrusted morph of $M$. alcicornis (average nucleotide difference of approximately $8.4 \%$ ). The two morphotypes of $M$. alcicornis shared 9 segregating sites with an average nucleotide difference of $6.9 \%$. Fiftyfive to fifty-nine fixed differences were identified among M. squarrosa and the other species (Additional file 7) with an average of 63 nucleotide differences. $M$. 
squarrosa was the most distinct species with approximately $25 \%$ of sequence divergence from the other two species.

The phylogenetic reconstruction based on Bayesian inference of the COI haplotypes assigned most colonies to three major clades (A, B, and C); M. squarrosa (E) and M. striata (D) formed separate clades (Figure 4). None of the major clades supported monophyletic divisions based on morphology. Eight colonies of the branched morph of $M$. alcicornis formed one clade $(\mathrm{C}, \mathrm{Pp}=71)$; however, two colonies of the branched morph of $M$. alcicornis (MabMg2 and MabML1) were embedded in the other clades. In addition, the recovered clades did not correspond to the classification resulting from the micromorphology analyses. For example, in the species $M$. complanata, the clade containing colonies McE8, McMg6, McMg9, and Mc123 had dactylopores with similar diameters with the exception of colony McMg9 (Figure 4A; Figure six in Ruiz-Ramos (2009)). On the other hand, the clade formed by different morphs of $M$. alcicornis (MabML1 and MaeLP2) had dactylopores with equal diameter.
Five of the six colonies that were misclassified with the DFA (Figure 3) were placed within clades of the same morphology (Figure 4). McMg3 clustered with McMg1 in clade A. Mab1 and MabT23 clustered with the other samples of M. alcicornis branched in clade C. MaeLP3 and MaeLP5 were placed in clade B. MaeMg1 was placed in cluster A.

The NJ analysis gave similar results to the BI phylogeny; the same main clusters (now A, D, and E, Additional file 8) were recovered. Results based on ML analysis are not shown because the phylogenetic tree was greatly unresolved.

\section{Caribbean-wide phylogeny}

The Caribbean-wide phylogeny was estimated from all Millepora colonies used for the morphological measurements and from 342 additional specimens of $M$. complanata and the two morphs of $M$. alcicornis (Figure 6). A total of 178 haplotypes were recovered from the sampled Millepora colonies, and 68\% of them (121) were unique sequences. Twenty-one haplotypes (Figure 5) were shared among two or more morphotypes or species.

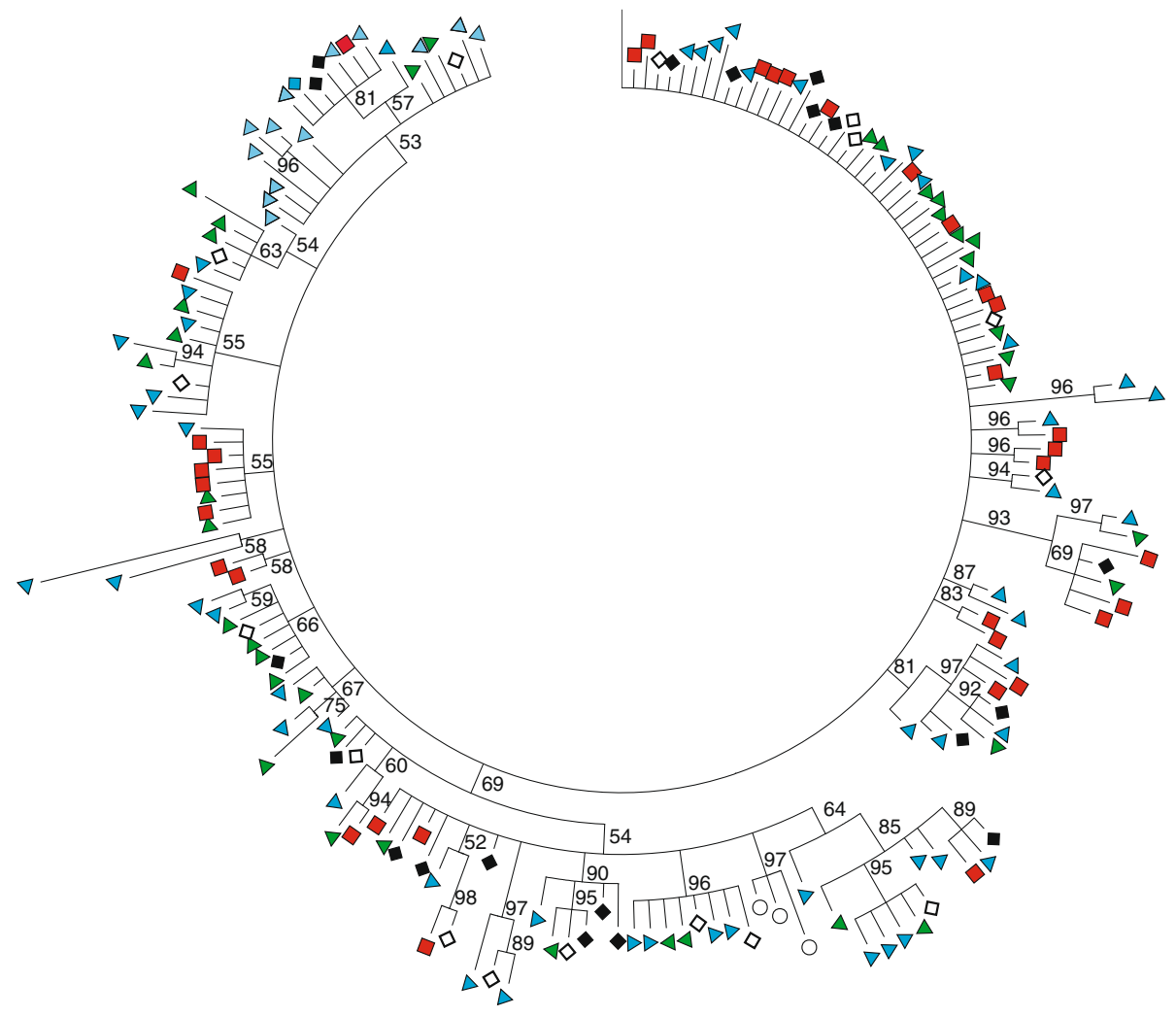

Figure 6 Caribbean-wide phylogeny of Millepora based on Bayesian analysis of COI haplotypes. Posterior probabilities over $50 \%$ are shown. Shapes represent morphotypes: red square, M. complanata; upside blue triangle, M. alcicornis branched morph; green downside triangle, M. alcicornis encrusted morph; circle, M. striata; diamond, haplotypes shared among M. alcicornis branched and M. alcicornis encrusted; black diamond, haplotypes shared among all the morphotypes. M. squarrosa and the hydrozoan Clytia elsaeoswaldae [GenBank:DQ064800] was used as the outgroup. 
Of the 10 most common haplotypes, five were shared among different morphotypes or species. The specimens of $M$. striata yielded distinct haplotypes; one of them was shared with both $M$. alcicornis and $M$. complanata. Nine main clades were recovered, and as in the previous phylogenies, none of the species were monophyletic (Figure 6). The resulting phylogeny was not concordant with morphologically based species assignments of the colonies, neither with the geographic origin of the samples.

\section{Analysis of molecular variances}

An AMOVA test was applied to a portion of the Caribbean data used for the phylogeny analysis (Additional file 9). Samples across the Caribbean from three species (M. alcicornis, M. complanata, and $M$. striata) were added for a total of seven populations (Mona, La Parguera reef system, Vieques, Panama, Guadeloupe, Grand Cayman, Curaçao). The highest percentage of variation was found within the Caribbean region (89.89\%). Significant levels of differentiation were detected among morphotypes within populations $\left(\Phi_{\mathrm{SC}}=0.067\right)$, among populations $\left(\Phi_{\mathrm{CT}}=\right.$ 0.037), and within the Caribbean $\left(\Phi_{\mathrm{ST}}=0.101\right.$ ) (Additional file 9). None of the different morphotypes within a population was significantly different from each other (Additional file 10). In contrast, populations were significantly different across the Caribbean, with some of the populations, such as Vieques and Culebra, being only $14 \mathrm{~km}$ apart (Additional file 10).

\section{Discussion}

The goals of this study were to genetically delineate the four recognized species of Caribbean Millepora (M. alcicornis, M. complanata, M. striata, and M. squarrosa). The molecular data suggested that three species of Millepora exist in the Caribbean: $M$. squarrosa, M. striata, and the complex composed of M. alcicornis and M. complanata. M. squarrosa is highly differentiated at the mitochondrial level from the other species. M. striata is closely related to $M$. alcicornis and $M$. complanata since one of its four haplotypes was shared with the species complex. To improve the resolution of the species relationships, we used a multicharacter approach (genetic and morphological data) to discriminate between $M$. alcicornis and M. complanata. Analysis of variances of micro-morphological traits showed high variation between $M$. complanata, $M$. alcicornis branched, and $M$. alcicornis encrusted and also among colonies within each morphotype. Dactylopore diameter and distance between gastropores were the only traits in which variation among morphotypes was higher than variation within morphotypes, therefore reliably separating the three morphotypes.

The genetic data was characterized by an unexpected high variability in the COI region; however, the pattern of variation was unrelated to colony shape. The relationships among COI haplotypes recovered by Bayesian inference and neighbor joining were independent of the morphology. Our sampling design had limitations and favored comparisons between M. alcicornis and M. complanata because they were the dominant milleporids in the sampling locations. M. squarrosa populations were decimated from reefs off La Parguera during the bleaching event of 2005, and only a couple colonies were found, so no morphological analyses were undertaken.

These findings question the current status of Millepora species in the Caribbean. The limited number of samples showed high morphological variability within and among taxa in the characters measured. However, the genetic results did not support the separation of four species. The presence of intermediate forms and excessive sharing of haplotypes between $M$. alcicornis and $M$. complanata and partially with $M$. striata suggest that these are not discrete species. Whether these morphotypes are ecotypes of one single species, species in the process of divergence or hybrids requires further study. In contrast, $M$. squarrosa stands as a distinct species, and its basal position in the phylogeny suggests that this species is an ancestor of the other Caribbean species. The limited distribution of this species is curious and worth investigating.

For the genetic analysis, Millepora colonies were collected from Panama (M. striata, M. complanata, and the two $M$. alcicornis morphs), Puerto Rico (all except $M$. striata), Curaçao, Guadeloupe, and Grand Cayman (all except M. striata and M. squarrosa), while the morphometric analysis included Millepora colonies from only one location (La Parguera, Puerto Rico). Ideally, a comprehensive study of morphological variation in Caribbean Millepora should include several more locations encompassing the known distribution of each species. In very closely related species, the species boundaries may vary according to the geographic origin of the samples as it has been demonstrated in the Orbicella annularis (previously Montastraea annularis) complex (Fukami et al. 2004). These authors showed that Orbicella faveolata, O. annularis, and Orbicella franksi were genetically and morphologically different in Panama, whereas in the Bahamas, all three species show some degree of genetic and morphological convergence. Subsequently, Levitan et al. (2011) found colonies in Panama that are morphologically similar to $O$. franksi but genetically associated with $O$. annularis. Similarly, we find ambiguous boundaries in the Caribbean Millepora; however, we recognize that our sampling regime does not cover the known distribution of Millepora.

Previous authors have noted high intraspecific variability in the micro-morphological traits of Millepora, despite their usefulness. Boshma (1948) suggested that 
colony shape was the only character distinct enough to be useful in the taxonomic classification of the genus. Other studies (e.g., Martínez-Estalella 1982) concluded that the use of skeletal traits was impractical due to their high intraspecific variation. However, de Weerdt (1984) suggested that the size and density of dactylopores could have some taxonomic value when used in combination with colony shape. M. alcicornis, M. complanata, and intermediate growth forms found in San Salvador, Bahamas were discriminated morphologically on the basis of skeletal micro-structures (Squiers et al. 2011). ITS sequences revealed contradictory results, as preassigned specimens of the two Bahamian Millepora species were also partitioned into different genetic clades (Squiers et al. 2011). Our results corroborate those of de Weerdt (1984), when only one micro-morphological character was used; high variability among colonies within and across species was evident. Nevertheless, caution must be exercised as the traits were very variable, and some overlapping was observed among colonies of different morphologies. Additionally, some of the five characters used in the analysis may covary, therefore violating the assumption of character independence.

\section{Phenotypic plasticity and the environment}

In marine environments, water energy, light availability and sediment transport have been shown to influence the development and survival of the organisms (Yoshioka and Yoshioka 1989, 1991). The different morphologies of Millepora have been attributed to the different environmental regimes along the reef structure (de Weerdt 1981; Vago et al. 1994; Kaandorp 1999). Generally, delicate branching types are distributed in calm or deep waters, while blade-like and encrusting morphs are conspicuous in high-energy environments such as the reef crest (Lewis 2006). In the reef crest, Millepora is a fast colonizer of the substratum; a bladed morphology may limit the water impact and drag force while attaining more surface area to trap light and plankton. In habitats with limited substrate, a branching morphology facilitates exploitation of the resources in the water column, increasing the surface area for feeding and light exposure (Coates and Jackson 1986; Harper 1986; Todd 2008). Additionally, branches can be advantageous in high-energy environments because fragmentation may help the coral to colonize and monopolize extensive habitats and increase the number of ramets (Jackson 1986; Harper 1986). In the case of M. alcicornis, branches may also help to localize, reach, and overgrow weaker space competitors, such as Plexaura homomalla (Wahle 1980) and Gorgonia ventalina. The overgrowth of G. ventalina by $M$. alcicornis may be associated with an increase of the surface area of the hydrozoan colony and, perhaps, a decrease of the energy expended in calcification.
The individual zooids may be affected by the microenvironmental conditions, showing variability in the size of the zooids within a colony. For example, the amount of light received by the zooids in the upper and lower parts of the colonies can be different, and consequently, growth rates of the zooids may also differ. In addition, the types of substratum being covered could modify the shape and size of the zooids in encrusted forms of Millepora.

In this study, the morphotypes of $M$. complanata, $M$. alcicornis branched, and $M$. alcicornis encrusted were recovered with the DFA, suggesting a relationship between microskeletal characters and colony shape. Dactylopore diameter and the distance between gastropores were the most diagnostic characters. Diameter of the gastropore also influenced the clustering. Whether the environment influences the morphotypes needs further investigation. Previous transplantation experiments have provided evidence for the ability of Millepora to change the colony shape when different environmental conditions are encountered (de Weerdt 1981; Meroz-Fine et al. 2003). However, the presence of different morphotypes occurring side by side in the reef suggests that part of this morphological plasticity is genetically controlled.

\section{Genetic variation}

High intraspecific variability was not only observed at the phenotypic level but also at the molecular level; COI sequences showed high levels of polymorphism with $68 \%$ of the sequences being unique haplotypes. Despite the high number of haplotypes, sequences were not divergent enough to distinguish among species. M. squarrosa was an exception, as it was very different from the other morphs, with an average of 56 fixed mutations (25\% difference). In general, genetic differentiation was higher within Caribbean populations than among the different morphotypes. However, pairwise differences were significant for $M$. striata and M. alcicornis from Panama, and M. alcicornis and M. complanata from La Parguera (SW) and Culebra. The lack of genetic differentiation among M. complanata and M. alcicornis provides evidence for a species complex with some geographical differentiation. Phylogenetic and haplotype network analyses did not recover a monophyletic $M$. striata even though significant, but small pairwise differences were found between $M$. striata and the complex M. complanata-M. alcicornis. Therefore, more data is needed to determine whether $M$. striata belongs to the species complex.

In the Red Sea, Millepora dichotoma exhibited four recognized morphotypes: delicate branched, blade-like branched, encrusting, and box-work morphs (Vago et al. 1998). Molecular studies (Meroz-Fine et al. 2003) showed that the four morphotypes consisted of two species; each 
species was represented by two different morphotypes. Similar results were found for the Millepora species occurring in Vietnam (Manchenko et al. 1993). Our study revealed similar patterns in the Caribbean, where the branched (M. alcicornis) and bladed (M. complanata) morphs were genetically indistinguishable with a neutral molecular marker. The cross-blade $M$. striata gave inconclusive results. The thick box-work $M$. squarrosa was the only distinct species.

Mitochondrial DNA is highly conserved within scleractinian corals (Anthozoa) (Shearer et al. 2002; Hellberg 2006), but for Millepora and other members of the Medusozoa (sister group to Anthozoa), the rate of mitochondrial DNA evolution is similar to those found in the Bilateria (Govindarajan et al. 2005; Hellberg 2006). The COI was successfully used to identify sibling species within the Medusozoa (Dawson and Jacobs 2001; Govindarajan et al. 2005). The analyzed portion of the COI gene (385 bp) contained 84 variable sites, of which 75 were parsimony informative, confirming the usefulness of mtDNA in species-level phylogenies in Medusozoa. Therefore, the lack of genetic divergence among $M$. alcicornis, $M$. complanata, and $M$. striata is not a consequence of low levels of mtDNA variation.

None of the mutations were fixed among $M$. alcicornis, M. complanata, and M. striata, but more than 50 mutations were fixed in $M$. squarrosa. Sequence divergence ranged from $22 \%$ to $25 \%$ among $M$. squarrosa and the other morphotypes, and from $0 \%$ to $3 \%$ between M. alcicornis, M. complanata, and M. striata. Values of sequence divergence $\geq 4 \%$ in the mtDNA were previously considered as a threshold for the distinction among species (Dawson and Jacobs 2001; Knowlton and Weigt 1998).

\section{Taxonomical and genetic incongruence of the $M$. complanata-M. alcicornis complex}

The multicharacter approach (e.g., morphological, molecular, behavioral, life history strategy, and reproductive biology) in corals has been shown to successfully differentiate species, which could not be distinguished with one set of characters (Knowlton et al. 1992; van Veghel and Bak 1993; Weil and Knowlton 1994; Levitan et al. 2004). Our two-character approach (morphology and genetics) was inconclusive. The morphological characters agreed with the prevailing taxonomic status of $M$. complanata and $M$. alcicornis; morphological samples from $M$. squarrosa and M. striata need to be compared. The genetic data suggest $M$. that squarrosa is a distinct species.

Studies in corals highlight the limitation of applying a particular species concept in a group of recently divergent taxa (e.g., Orbicella, Pacific Acropora) that occupy similar habitats, exhibit phenotypic plasticity, and have no temporal and physical reproductive barriers (i.e., during mass spawning). Orbicella species are morphologically distinct, but intermediate morphs can be found (Weil and Knowlton 1994). Orbicella spp. are composed of three sibling species (Weil and Knowlton 1994), but evidence for a single species in Curaçao and Florida had been suggested by others (van Veghel and Bak 1993; Medina et al. 1999). Follow-up studies showed that the geographical differences in the complex were due to a latitudinal hybridization gradient through the Western Atlantic (Fukami et al. 2004; Levitan et al. 2011).

The application of a species concept in Millepora complanata and M. alcicornis, two widely distributed milleporids in the Caribbean, is equally problematic. The biological species concept cannot be tested yet due to lack of studies on the reproduction of Millepora. M. complanata and $M$. alcicornis formed paraphyletic clusters in the phylogenetic tree; therefore, the taxa did not meet the species criteria according to the phylogenetic species concept either. Additional support for this assertion is stemming from an independently involved nuclear ribosomal region (ITS), which resulted in clades containing both Millepora species and intermediate forms (Squiers et al. 2011; Tepper et al. 2012).

Whether the Millepora species are a single evolutionary entity or an example of incipient speciation or reticulate evolution is unknown. The presence of intermediate forms and the paraphyly of Millepora species indicate the possibility of reticulate evolution, which is a common phenomenon in corals (Veron 1995; Hatta et al. 1999; van Oppen et al. 2000; Richards et al. 2008). On the other hand, if $M$. alcicornis and M. complanata are undergoing speciation, lineage sorting of the COI (this study) and ITS region (Squiers et al. 2011; Tepper et al. 2012) is still incomplete, suggesting recent divergence.

\section{Conclusions}

This study suggests that the Caribbean milleporids include two species, $M$. squarrosa and the species complex of $M$. alcicornis-M. complanata. More information is needed to delineate $M$. striata. The morphological analysis of $M$. squarrosa and M. striata is recommended. The use of other molecular markers and the integration of reproduction studies along geographical gradients may help to describe the Millepora species complex.

\section{Additional files}

Additional file 1: List of the samples used for the morphological and genetic analysis. Code name used throughout the study, morphotype, name of reef, zone within the reef, and depth (in meters) in which the colony was found.

Additional file 2: The reef system of La Parguera, southwestern Puerto Rico. All colonies were sampled from the front reef of the 
Enrique $\left(17.954^{\circ} \mathrm{N}, 67.051^{\circ} \mathrm{W}\right)$, Media Luna $\left(17.938^{\circ} \mathrm{N}, 67.041^{\circ} \mathrm{W}\right)$, Las Pelotas $\left(17.956^{\circ} \mathrm{N}, 67.073^{\circ} \mathrm{W}\right)$, Turrumote $\left(17.934^{\circ} \mathrm{N}, 67.018^{\circ} \mathrm{W}\right)$, and Margarita $\left(17.922^{\circ} \mathrm{N}, 67.097^{\circ} \mathrm{W}\right)$ reefs.

Additional file 3: Morphotypes of Millepora alcicornis. Left: M. alcicornis free growth branching; right: $M$. alcicornis encrusted on gorgonians.

Additional file 4: Measured traits of coralla in Millepora alcicornis (MabT22): g, gastropore; d, dactylopore; 1, diameter of gastropore; 2 , diameter of dactylopore; 3 , distance among dactylopores; 4, distances from gastropore to the nearest dactylopore; 5, distances among gastropores.

Additional file 5: Genetic diversity and summary statistics based on COI sequences. $\mathrm{N}$, number of samples; $\mathrm{S}$, segregating sites; $\mathrm{M}$, mutations; S.S., synonymous sites; N.S., non-synonymous sites; $\mathrm{H}$, number of haplotypes; $\mathrm{Hd}$, haplotype diversity; $\pi$, nucleotide diversity; $\theta_{w}$, Watterson's theta; $\mathrm{SD}$, standard deviation.

Additional file 6: Variability (mean, median, and 5th and 95th percentiles) in the skeletal traits of Millepora. The top graph shows variability in distances among dactylopores, the center graph shows variability in distances from gastropore to the nearest dactylopore, and the bottom graph shows variability in distances between gastropores. The solid line is the median, and the dashed line is the mean. The white boxes represent $M$. complanata $(\mathrm{Mc})$, boxes with vertical lines is $M$. alcicornis branched (Mab), and boxes with diagonal lines is M. alcicornis encrusted (Mae). Letters above the boxes are values of Tukey's test; significant differences among positions are denoted by different letters.

Additional file 7: Estimates of $\mathrm{COI}$ divergence among the species and morphotypes of Millepora. M. striata, M. squarrosa, M. complanata, and $M$. alcicornis ( $b$ is the branching morphotype,

$e$ is the encrusted morphotype).

Additional file 8: Neighbor joining phylogeny of Millepora colonies used for morphological analyses (based on COI sequences). Posterior probabilities over 50\% are shown. Shapes represent morphotypes: square, M. complanata; upside triangle, M. alcicornis branched morph; downside triangle, M. alcicornis encrusted morph; circle, M. striata; diamond, $M$. squarrosa. Names of specimens have been color-coded as in Figure 4. The hydrozoan Crapedacusta spp. is used as outgroup [GenBank: FJ423620].

Additional file 9: Analysis of molecular variances (AMOVA) of Millepora species and morphotypes. Comparisons of morphotypes were made within the Caribbean basin, among populations, and among morphotypes within populations. Populations were sampled from Panama, Grand Cayman, Mona, La Parguera reef system, Vieques, Guadeloupe, and Curaçao. $\Phi_{\text {ST }}$ values were obtained by randomization of 25,000 permutations Bonferroni corrected. ${ }^{*} p<0.002,{ }^{* *} p<0.0001$ Fixation indices $\Phi_{S C}=0.066^{* *}, \Phi_{S T}=0.101^{* *}, \Phi_{C T}=0.037^{*}$.

Additional file 10: Pairwise comparisons (Tamura-Nei distance) of Millepora populations assigned by morphotypes. MC, M. complanata; Ms, M. striata; Mab, M. alcicornis branched; Mae, M. alcicornis encrusted; Pa, Panama; GC, Grand Cayman; Mo, Mona; SW, La Parguera Reef System; Vi, Vieques; Gd, Guadeloupe. Significant values $(p<0.01)$ are in bold.

\section{Abbreviations}

BI: Bayesian inference; COl: cytochrome oxidase I; Mab: Millepora alcicornis branched; Mae: Millepora alcicornis encrusted; Mc: Millepora complanata: MS: Millepora striata; PR: Puerto Rico.

\section{Competing interests}

The authors declare they have no competing interests.

\section{Authors' contributions}

DVRR and NVS conceived and designed the study. DVRR collected and processed the samples, analyzed the data, and drafted the manuscript. NVS collected samples, supervised the study, and helped analyze the data and draft the manuscript. EW collected samples, supervised the morphological analysis, and helped draft the manuscript. All authors read and approved the final manuscript.

\section{Acknowledgements}

The authors thank A. Croquer, M. Hellberg, T. Ridgway, M. Rojas, and H. Torres-Pratts for assistance in sample collections. C. Prada and P. Yoshioka commented on an earlier version of the manuscript. Monetary support was provided by the Caribbean Coral Reef Institute Grant to NVS. DNA sequencing was performed in the Sequencing and Genotyping Facility, University of Puerto Rico Río Piedras which is supported in part by NCRR AABRE Grant \#P20 RR16470 and NIH-SCORE Grant \#S06GM08102NSF-CREST and Grant \#0206200. Partial financial support was provided by the Department of Marine Sciences, University of Puerto Rico Mayagüez, the CRES-NOAA Coastal Ocean Program award \#NA17OP2919 to the University of Puerto Rico, and the Global Environment Facility (GEF) and World Bank Coral Reef Targeted Research and Capacity Building program through the Coral Disease Working Group to EW.

\section{Author details}

'Department of Marine Sciences, University of Puerto Rico, Mayagüez, Call Box 9000, Mayagüez 00681, Puerto Rico. ${ }^{2}$ Current address: 208 Mueller Laboratory, Biology Department, The Pennsylvania State University, University Park, PA 16801, USA

Received: 15 October 2013 Accepted: 13 January 2014

Published: 20 January 2014

\section{References}

Amaral FD, Broadhurst MK, Cairns SD, Schlenz E (2002) Skeletal morphometry of Millepora occurring in Brazil, including a previously undescribed species. Proc Biol Soc Wash 115:681-695

Amaral FD, Steiner AQ, Broadhurst MK, Cairns SD (2008) An overview of the shallow-water calcified hydroids from Brazil (Hydrozoa: Cnidaria), including the description of a new species. Zootaxa 1930:56-68

Boshma H (1948) The species problem in Millepora. Zool Verhandel 1:3-115 Cairns SD (1999) Species richness of recent Scleractinia. Atoll Res Bull 459:1-46

Clement M, Posada D, Crandall K (2000) TCS: a computer program to estimate gene genealogies. Mol Ecol 9:1657-1660

Coates AG, Jackson JBC (1986) Morphological themes in the evolution of clonal and aclonal marine invertebrates. In: Jackson JBC, Buss LW, Cook RE (eds) Population biology and evolution of clonal organisms. Yale University Press, New Haven, Massachusetts, p 67

Dawson MN, Jacobs DV (2001) Molecular evidence for cryptic species of Aurelia aurita (Cnidaria, Scyphozoa). Biol Bull 200:92-96

de Weerdt WH (1981) Transplantation experiments with Caribbean Millepora species (Hydrozoa, Coelenterata) including some ecological observations on growth forms. Bijdr Dierkd 51:1-19

de Weerdt WH (1984) Taxonomic characters in Caribbean Millepora species (Hydrozoa, Coelenterata). Bijdr Dierkd 54:243-262

de Weerdt WH (1990) Discontinuous distribution of the tropical West Atlantic hydrocoral Millepora squarrosa. Beaufortia 41:195-203

Edmunds PJ (1999) The role of colony morphology and substratum inclination in the success of Millepora alcicornis on shallow coral reefs. Coral Reefs 18:133-140

Excoffier L, Larval G, Schneider S (2005) Arlequin ver. 3.0: an integrated software package for population genetics data analysis. Evol Bioinform 1:47-50

Excoffier L, Smouse PE, Quattro JM (1992) Analysis of molecular variance inferred from metric distances among DNA haplotypes: application to human mitochondrial DNA restriction data. Genetics 131:479-491

Felsenstein J (1985) Confidence limits on phylogenies: an approach using the bootstrap. Evolution 39:783-791

Fenner D (1999) New observations on the stony coral (Scleractinia, Milleporidae, and Stylasteridae) species of Belize (Central America) and Cozumel (Mexico) Bull Mar Sci 64:143-154

Fukami H, Budd AF, Levitan DR, Jara J, Kersanach R, Knowlton N (2004) Geographic differences in species boundaries among members of the Montastraea annularis complex based on molecular and morphological markers. Evolution 58:324-337

Glynn PW (1993) Coral reef bleaching: ecological perspectives. Coral Reefs 12:1-17

Govindarajan AF, Halanych KM, Cunningham CW (2005) Mitochondrial evolution and phylogeography in the hydrozoan Obelia geniculata (Cnidaria). Mar Biol 146:213-222

Harper JL (1986) Modules, branches and the capture of resources. In: Jackson JBC, Buss LW, Cook RE (eds) Population biology and the evolution of clonal organisms. Yale University Press, New Haven, Massachusetts, p 1 
Hatta M, Fukami H, Wang W, Omori M, Shimoike K, Hayashibara T, Ina Y, Sugiyama T (1999) Reproductive and genetic evidence for a reticulate evolutionary history of mass-spawning corals. Mol Biol Evol 16:1607-1613

Hellberg ME (2006) No variation and low synonymous substitution rates in coral mtDNA despite high nuclear variation. BMC Evol Biol 6:24

Jackson JBC (1986) Distribution and ecology of clonal and aclonal benthic invertebrates. In: Jackson JBC, Buss LW, Cook RE (eds) Population biology and evolution of clonal organisms. Yale University Press, New Haven, Massachusetts, pp 297-356

Kaandorp JA (1999) Morphological analysis of growth forms of branching marine sessile organisms along environmental gradients. Mar Biol 134:295-306

Kimura M (1968) Evolutionary rate at the molecular level. Nature 217:624-626

Knowlton N, Weigt A (1998) New dates and new rates for divergence across the Isthmus of Panama. Proc R Soc Lond B 265:2257-2263

Knowlton N, Weil E, Weight LA, Guzmán HM (1992) Sibling species in Montastraea annularis, coral bleaching, and the coral climate record. Science 255:330-333

Levitan DR, Fukami H, Jara J, Kline D, McGovern TM, McGhee KE, Swanson CA, Knowlton N (2004) Mechanisms of reproductive isolation among sympatric broadcast-spawning corals of the Montastraea annularis species complex. Evolution 58:308-323

Levitan DR, Fogarty ND, Jara J, Lotterhos KE, Knowlton N (2011) Genetic, spatial, and temporal components of precise spawning synchrony in reef building corals of the Montastraea annularis species complex. Evolution 65:1254-1270

Lewis JB (1989) The ecology of Millepora. Coral Reefs 8:99-107

Lewis JB (1992) Heterotrophy in corals: zooplankton predation by the hydrocoral Millepora complanata. Mar Ecol Prog Ser 90:251-256

Lewis JB (2006) The biology and ecology of the hydrocoral Millepora on coral reefs. Adv Mar Biol 50:1-55

Maddison WP, Maddison DR (2000) Macclade 4: analysis of phylogeny and character evolution. Sinauer Associates Inc, Sunderland, Massachusetts

Manchenko GP, Moschenko AV, Odintsov VS (1993) Biochemical genetics and systematics of Millepora (Coelenterata: Hydrozoa) from the shore of south Vietnam. Biochem Syst Ecol 21:729-735

Marshall PA, Baird AH (2000) Bleaching of corals on the Great Barrier Reef: differential susceptibilities among taxa. Coral Reefs 19:155-163

Martínez-Estalella N (1982) Sistemática del género Millepora (Hydrozoa: Milleporidae) y datos sobre algunos organismos asociados. Poeyana 246:1-27

Medina M, Weil E, Szmant A (1999) Examination of the Montastraea annularis species complex (Cnidaria: Scleractinia) using ITS and COI sequences. Mar Biotech 1:89-97

Meroz-Fine E, Brickner I, Loya Y, Ilan M (2003) The hydrozoan coral Millepora dichotoma: speciation or phenotypic plasticity? Mar Biol 143:1175-1183

Paulay G, Benayahu Y (1999) Patterns and consequences of coral bleaching in Micronesia (Majuro and Guam) in 1992-1994. Micronesica 31:109-124

Posada D, Crandall KA (1998) MODELTEST: testing the model of DNA substitution. Bioinformatics 14:817-181

Razak TB, Hoeksema BH (2003) The hydrocoral genus Millepora (Hydrozoa: Capitata: Milleporidae) in Indonesia. Zool Verhandel 345:313-336

Richards ZT, Oppen MJH, Wallace CC, Willis BL, Miller DJ (2008) Some rare Indo-Pacific coral species are probable hybrids. PLOS ONE 3:1-7

Ronquist F, Huelsenbeck JP (2003) MrBayes 3: Bayesian phylogenetic inference under mixed models. Bioinformatics 19:1572-1574

Rozas J, Sánchez-DelBarrio JC, Messeguer X, Rozas R (2003) DnaSP, DNA polymorphism analyses by the coalescent and other methods. Bioinformatics 19:2496-2497

Ruiz-Ramos DV (2009) Morphological and genetic variation in the Caribbean species of the hydrocoral genus Millepora. University of Puerto Rico, Mayagüez, Dissertation

Shearer TL, Van Oppen MJH, Romano SL, Worheide G (2002) Slow mitochondrial DNA sequence evolution in the Anthozoa (Cnidaria). Mol Ecol 11:2475-2487

Squiers L, Hay C, Gorbach D, Friend D, Black B, Greenstein B, Strychar K, Tepper C (2011) Cryptic speciation: a mismatch between genetics and morphology in Millepora. The 13th Symposium on the Natural History of the Bahamas 13:8-19

Swofford DL, PAUP* (2002) Phylogenetic analysis using parsimony*, version 4.0b10. Sinauer Associates Inc, Sunderland, Massachusetts

Tajima F (1989) Statistical method for testing the neutral mutation hypothesis by DNA polymorphism. Genetics 123:585-595

Tamura K, Nei M (1993) Estimation of the number of nucleotide substitutions in the control region of mitochondrial DNA in humans and chimpanzees. Mol Biol Evol 10:512-526
Tepper C, Squiers L, Hay C, Gorbach D, Friend D, Black B, Greenstein B, Strychar K (2012) Cryptic species: a mismatch between genetics and morphology in Millepora. Mar Sci 2:57-65

Todd PA (2008) Morphological plasticity in scleractinian corals. Biol Rev 83:315-337

Vago R, Shai Y, Ben-Zion M, Dubinsky Z, Achituv Y (1994) Computerized tomography and image analysis: a tool for examining the skeletal characteristics of reef building organisms. Limn Oceanogr 39:448-452

Vago R, Achituv Y, Vaky L, Dubinsky Z, Kizner Z (1998) Colony architecture of Millepora dichotoma Forskal. J Exp Mar Biol Ecol 224:225-235

Van Oppen MJH, Willis BL, van Vugt HWJA, Miller DJ (2000) Examination of species boundaries in the Acropora cervicornis group (Scleractinian, Cnidaria) using nuclear DNA sequence analyses. Mol Ecol 9:1363-1373

Van Veghel MLJ, Bak RPM (1993) Intraspecific variation of a dominant Caribbean reef building coral, Montastraea annularis: genetic, behavioral and morphometric aspects. Mar Ecol Prog Ser 92:255-265

Veron JEN (1995) Corals in space and time: the biogeography and evolution of the Scleractinia. Cornell University Press, Ithaca, New York

Wahle CM (1980) Detection, pursuit, and overgrowth of tropical gorgonians by milleporid hydrocorals: Perseus and Medusa revisited. Science 209:689-691

Weil E, Knowlton N (1994) A multi-character analysis of the Caribbean coral Montastraea annularis (Ellis and Solander, 1786) and its two sibling species, M. faveolata (Ellis and Solander, 1786) and M. franksi (Gregory, 1895). Bull Mar Sci 55:151-175

Yoshioka PM, Yoshioka BB (1989) Effects of water motion, topographic relief and sediment transport on the distribution of shallow-water gorgonian community. Mar Ecol Prog Ser 54:257-264

Yoshioka PM, Yoshioka BB (1991) A comparison of the survivorship and growth of shallow-water gorgonian species of Puerto Rico. Mar Ecol Prog Ser 69:253-260

doi:10.1186/1810-522X-53-4

Cite this article as: Ruiz-Ramos et al:: Morphological and genetic evaluation of the hydrocoral Millepora species complex in the Caribbean. Zoological Studies 2014 53:4.

\section{Submit your manuscript to a SpringerOpen ${ }^{\odot}$ journal and benefit from:}

- Convenient online submission

- Rigorous peer review

- Immediate publication on acceptance

- Open access: articles freely available online

- High visibility within the field

- Retaining the copyright to your article

Submit your next manuscript at $>$ springeropen.com 